\title{
Gênero e Feminismos: conceitos e perspectivas
}

\author{
Gender and Feminist: Concepts and Perspectives
}

\author{
Marcella Barbosa Miranda Teixeira ${ }^{1}$ \\ Fernanda Tarabal Lopes ${ }^{2}$ \\ Admardo Bonifácio Gomes Júnior ${ }^{3}$
}

\begin{abstract}
RESUMO
Este artigo tem por objetivo apresentar as diferentes abordagens epistemológicas nos estudos sobre gênero e sobre os movimentos feministas, com o intuito de mostrar as diferentes visões acerca das perspectivas utilizadas. Isso se dá pelo fato de existir uma pluralidade de formas e categorias dadas aos conceitos de gênero e feminismos.

PALAVRAS-CHAVE: Feminismos. Gênero. Mulheres.
\end{abstract}

\section{ABSTRACT}

This theorical article has the purpose to presente the differents epistemological approaches in the gender studies and in the feminist movements, with the intention of showing the differents visions about the used perspectives. There are a lot of forms and categories about concepts of gender and feminisms..

KEYWORDS: Feminist. Gender. Women.

\section{Introdução}

A discussão histórica produzida sobre a categoria Gênero tem implicado em diversas perspectivas, abordagens e impasses entre as pesquisadoras e as feministas. O que se vê são posicionamentos distintos, mostrando a dinamicidade e complexidade dessa área de estudo. Nesse

\footnotetext{
1 Mestre no Programa de Pós-graduação em Administração do CEFET/MG, Brasil. E-mail: marcellabmt@ufop.edu.br

2 Docente no Programa de Pós-graduação em Administração do CEFET/MG, Brasil. E-mail: fernanda.tarabal@ufrgs.br

3 Docente no Programa de Pós-graduação em Administração do CEFET/MG, Brasil. E-mail: admardo.jr@gmail.com
} 
sentido, há a necessidade de um maior diálogo sobre essa temática, permitindo um olhar crítico sobre as teorias criadas (BITENCOURT, 2013).

Considerando este cenário, este artigo tem como ponto de partida o entendimento de que o campo de estudos sobre gênero e feminismos necessita de uma revisão sobre as suas principais abordagens teóricas utilizadas, que esclareçam seus conceitos, semelhanças e diferenças. É importante, então, apresentar a conjuntura de todo o cenário do campo acadêmico, no que diz respeito à discussão de gênero e feminismos (COSTA; LIMA, 2015).

Dessa forma, pelo fato de haver tensões e debates claros nessas temáticas, o que buscamos com esse artigo é apresentar as diferentes abordagens epistemológicas nos estudos sobre gênero e feminismos, com o intuito de mostrar as visões acerca das diferentes perspectivas utilizadas. Para tanto, serão apresentadas as duas formas de utilização do conceito de gênero, bem como um histórico das ondas dos feminismos e suas principais abordagens.

A justificativa desta pesquisa está pautada na importância de se compreender as diversas perspectivas e abordagens relacionadas ao gênero e aos feminismos. Essa inquietação surgiu pela dificuldade da primeira autora deste artigo em abordar esses complexos e diversos conceitos em seu referencial teórico para a dissertação do mestrado, contribuindo então para um melhor entendimento e uma melhor organização na apresentação dessa temática para as futuras pesquisadoras.

Este artigo se divide em quatro capítulos. Primeiramente, esta introdução versando sobre o objetivo e justificativa deste estudo. Seguido pelos capítulos que abordam os conceitos de gênero e feminismo. Após, apresenta-se as considerações finais deste estudo e, por último, as referências utilizadas.

\section{Gênero: Uma Categoria em Debate}


Conforme afirma Costa e Lima (2015), a discussão de gênero é uma arena de constantes tensões e de diversos e distintos pensamentos e, por esse motivo, abrange questões sociais, culturais e históricas e está em constante processo de redefinição, ou seja, é mutável, em virtude das interações entre indivíduos (GROSSI, 2000). Amorim (2011) indaga que o gênero tem a finalidade de determinar tudo o que é definido socialmente, e por esse fato, está em constante processo de ressignificação pelas interações entre homens e mulheres, ou seja, é um "termo em construção" (CALÁS; SMIRCICH, 1999, p.275). Assim, Haraway (1995, p. 221) afirma que "gênero é um conceito desenvolvido para contestar a naturalização da diferença sexual em múltiplos terrenos de luta".

Com essas constantes mudanças e ressignificações de gênero, apresentam-se, então, duas diferentes formas que o conceito de gênero é e foi utilizado: a primeira forma é que a palavra gênero descreve a personalidade e o comportamento e o termo sexo, usado em oposição ao gênero, referencia o corpo, para diferenciar o que é socialmente construído (gênero) do que é biologicamente definido (sexo), ou seja, o sistema binário sexo/gênero, defendido pelas feministas da década de 1960; a segunda forma é a utilização da palavra gênero para referenciar qualquer construção social sobre a diferença entre o feminino e o masculino, inclusive considera o sexo como uma construção social, conceito defendido pelas feministas pósestruturalistas (NICHOLSON, 2000).

A primeira forma é o conceito ancorado na distinção binária de gênero e sexo desenvolvido por várias correntes dos movimentos feministas contemporâneos a partir dos anos de 1960 (SANTOS, 2010; PRAUN, 2011). Então se tem que "a construção dos relacionamentos e a definição dos papéis entre os gêneros ocorrem por meio da cultura, da criação social de ideias, normas e comportamentos esperados, tanto para os homens quanto para as mulheres" (LIMA, 2009, p.11). Isto é, o gênero como um produto cultural e o sexo como uma caracterização biológica (SOUZA, 2016). 
Lamas (2000, p. 13) afirma que esse conceito de gênero "permitiu a compreensão de que não é a anatomia que posiciona mulheres e homens em âmbitos e hierarquias distintos, e sim a simbolização que as sociedades fazem dela". Ou seja, esse conceito de gênero atribui à construção social a desigualdade existente entre homens e mulheres (SANTOS, 2010). Assim, "gênero serve, portanto, para determinar tudo que é social, cultural e historicamente determinado" (GROSSI, 2000, p. 5).

Nessa mesma perspectiva, Bruschini, Ardaillon e Unbehaum (1998, p. 89) conceituam gênero como:

Princípio que transforma as diferenças biológicas entre os sexos em desigualdades sociais, estruturando a sociedade sobre a assimetria das relações entre homens e mulheres. Usar "gênero" para todas as referências de ordem social ou cultural, e "sexo" para aquelas de ordem biológica (BRUSCHINI; ARDAILLON; UNBEHAUM, 1998, p.89).

De acordo com Praun (2011), é importante o reconhecimento da diferença no conceito de gênero e sexo, pois representa uma interrupção dos conceitos utilizados anteriormente nos trabalhos científicos, já que os estudos se limitavam às diferenças biológicas entre homens e mulheres e aos estereótipos de masculinidade e feminilidade, além de caracterizar as funções femininas como domiciliar e familiar.

Porém, "ao aceitarmos que a construção de gênero é histórica e se faz incessantemente, estamos entendendo que as relações entre homens e mulheres, os discursos e as representações dessas relações estão em constante mudança" (LOURO, 1997, p. 35). E com isso, as feministas pósestruturalistas passaram a considerar gênero como todas as formas de construção social, cultural e linguística com implicações na diferenciação de mulheres e homens, incluindo o sexo como uma construção social, com o objetivo de compreender gênero para além da dicotomia masculino-feminino, em sua segunda forma (MEYER, 2004). Essa nova percepção de gênero foi necessária para desconstruir os sistemas tradicionais ocidentais, com base 
no binarismo, e permitir o pensamento de pluralidades e diversidades (MARIANO, 2005).

Para Franzoni (2008) essa perspectiva marca uma ruptura teórica, com a queda do determinismo biológico, pelo fato de que, nessa visão, o corpo é como descoberta das ideias, dos discursos, das representações que constituem novas realidades: surge a pluralidade de gêneros, um novo sujeito do feminismo, multifacetado. Ou seja, para essa perspectiva, tanto corpo quanto gênero são construções sociais, históricas e culturais (SOUZA, 2016).

Esse pensamento pós-estruturalista foi idealizado originalmente por Foucault, em seus trabalhos sobre poder e saber e tem autores como Nicholson (2000) e Butler (2003). Para a última autora, a noção de gênero deve ser reformulada, ressignificada, já que a distinção de sexo e gênero, utilizada por outras abordagens feministas, indica uma descontinuidade entre corpos sexuados e gênero (BUTLER, 2003). Isso quer dizer que se deve descontruir o pensamento binário do homem e da mulher e as concepções de masculino e feminino, bem como negar os modelos de análise universais (LOURO, 1997; BUTLER, 2003; COSTA; LIMA, 2015).

A construção de homens não se aplica exclusivamente ao corpo masculino e da mesma forma que a de mulheres não se aplica necessariamente ao corpo feminino. Para Nicholson (2000), sexo e gênero não podem ser independentes, e por isso, tanto gênero quanto sexo são construções sociais, culturais e históricas. Lamas (2010, p. 15-16) reforça a visão de Butler acerca do gênero:

[...] como um fazer que constitui a identidade sexual. Para Butler gênero é um processo que articula sexo, desejo e prática sexual, no qual o corpo é moldado pela cultura através do discurso. Daí sua [sic] ideia da desconstrução do gênero como um processo de subversão cultural.

Dessa forma, Louro (1997, p. 24) entende gênero como um "constituinte da identidade dos sujeitos". Para a autora, devem-se 
considerar as diversas categorias e dimensões que constituem os sujeitos. $\mathrm{E}$ que essas identidades são plurais, múltiplas e estão sempre em construção e são instáveis e passíveis de transformação, e não são algo dado e definitivo e nem baseado em generalizações.

Franzoni (2008) concorda alertando para o fato de que embora todas as mulheres possam sofrer a discriminação de gênero, existem outros aspectos de suas identidades sociais, por exemplo, classe, cor, etnia, religião, orientação social, entre outros. Esses aspectos fazem diferença na maneira como os vários grupos de mulheres sofrem a discriminação. Então, tem-se a necessidade de se considerar esse conjunto de aspectos para as relações de gênero.

Nesse sentido, Butler (2003) afirma que gênero não se constituiu de forma coerente e consistente ao longo dos distintos contextos históricos pelo fato de haver interseções com essas diversas categorias e dimensões. Assim, é impossível separar gênero dos contextos políticos e culturais. Por esse motivo, as relações de gênero são desiguais na maioria das sociedades, pelos desequilíbrios existentes nas leis, nas políticas e nas práticas sociais e culturais, bem como nas atitudes e nos comportamentos dos sujeitos (AMORIM, 2011).

Para Butler (2003) gênero não deve ser uma marca para determinar os corpos e propõe a ideia de gênero como performance e performatividade, " [...] porque ele é algo que se faz e, não, algo que se tem ou se é" (TEIXEIRA, 2015, p. 265). Ou seja, gênero é um instrumento que produz identidades, como por exemplo, homem e mulher. Souza (2016, p. 28) afirma que gênero é "algo que se faz e desfaz por meio de processos altamente regulados por normas sociais”. É uma estrutura em que a normalização do feminismo e do masculino é realizada. (OLIVEIRA, 2008).

Essa ideia de gênero como performance e perfomatividade de Butler evidencia que gênero não é um atributo do sujeito, não é fixo e inato, mas sim um dispositivo de identidades que são formadas por normas e discursos sociais. A performatividade compreende os processos em que os sujeitos são 
construídos como sujeitos, ou seja, é uma produção discursiva. Já performance é a repetição das normas, é o ato limitado, não sendo uma escolha do sujeito (BUTLER, 2003; SOUZA, 2016).

Além disso, Scott (1995) faz uma crítica às visões tradicionais acerca de gênero, sendo uma delas a utilização do termo gênero como significado de mulher por alguns estudos feministas da década de 1960. Para a autora, mulher fazer parte do gênero, mas não significa gênero. Ao criticar a categoria 'mulher' dos estudos, Scott (1995) teve o objetivo de refutar o essencialismo biológico, o viés heterossexual dos estudos e entender as vivências e experiências como relacionais. Então, ao abordar gênero, deve-se também falar sobre os homens, pois o feminino sempre inclui o masculino e o masculino sempre inclui o feminino. Nesse sentido, na visão de Scott, as outras vertentes feministas da mesma maneira em que tentavam acabar com as diferenças sexuais, defendiam as mulheres, e dessa forma, acabavam paradoxalmente por reforçar a diferença sexual (SANTOS, 2008; FRANZONI, 2008; TEIXEIRA, 2015; SOUZA, 2016).

Por meio da abordagem pós-estruturalista, Scott (1995, p.86) constitui o gênero em duas proposições e em quatro elementos inter-relacionados entre si. São elas: (1) o gênero é constituído de relações sociais com base nas diferenças percebidas entre os sexos e (2) o gênero é uma forma primária de simbolizar as relações de poder. Para essa primeira divisão (1), a autora cita quatro subgrupos que são dependentes entre si:

a) representações culturalmente conhecidas e frequentemente contraditórias, como: Maria e Eva símbolo da mulher na tradição ocidental, interpretadas a partir de explicações culturais;

b) conceitos normativos (expressos em doutrinas religiosas, educativas, políticas, entre outras) que evidenciam a interpretações dos símbolos, tentando limitar as suas possibilidades metafóricas, ou seja, categoriza o significado do que é homem e mulher, do masculino e do feminino (representação binária); 
c) aspectos políticos referenciados às instituições e à organização social;

d) noção de identidade subjetiva, permitindo observar como as identidades de gênero são construídas, por meio da formação de conceitos, imagens e símbolos.

Guimarães (2005) explica que as contribuições de Scott são importantes para se perceber a categoria gênero, para analisar as relações entre mulheres e homens e também para verificar como elas influenciam na dinâmica social e política. Percebe-se como é difícil desconstruir as representações e os conceitos normativos, simbólicos, políticos e subjetivos. Nesse sentido, Scott (1995, p. 88) acredita que gênero é uma maneira primordial de dar sentido às relações de poder, ou seja, "o gênero é um campo primário no interior do qual, ou por meio do qual, o poder é articulado".

Desse modo, na perspectiva pós-estruturalista, gênero é entendido como um dispositivo de poder que constitui algumas identidades, entre elas, as de mulher e de homem (TEIXEIRA, 2015). Para Meyer (2004), o gênero não deve ser exclusivamente objeto de análise das condições de vida das mulheres (crítica também realizada por Scott), mas sim deve levar em consideração as relações de poder entre mulheres e homens, bem como as formas sociais e culturais que estabelecem os "sujeitos de gênero". Louro (1997) afirma que os gêneros produzem nas e pelas relações de poder.

Através da perspectiva do poder, tem-se mais uma crítica atribuída pelas feministas pós-estruturalistas ao pensamento binário que considera o homem e mulher em uma visão polarizada, relacionando-se dentro de uma lógica fixa e imutável de um homem dominante versus uma mulher dominada, eliminando qualquer possibilidade de resistência, de luta e do exercício de poder pelas mulheres (SCOTT, 1995; LOURO, 1997; BUTLER, 2003; TEIXEIRA, 2015).

Nessa visão, as feministas pós-estruturalistas se espelharam na "analítica de poder" de Foucault para negar as concepções tradicionais de 
centralidade e de posse do poder, já que para ele, o poder é exercido em muitas e variadas direções, constituindo-se por toda a sociedade, e não considera que apenas um polo tem o poder e esse é estável (LOURO, 1997). Assim, nessa concepção, o poder só é exercido entre os sujeitos que são capazes de resistir. Ou seja, para Foucault na relação de poder sempre há a resistência (SOUZA, 2014).

É nesse entendimento do exercício do poder que são constituídas as diferenças e desigualdades, e isso não exclui o fato de as mulheres terem sido subordinadas pelos homens, mas também inclui as lutas e resistências das mulheres para essa situação. Situação em que se confronta uma sociedade hegemônica branca, masculina, heterossexual e cristã, que são os sujeitos dotados de poder nas relações sociais, sendo uma categoria normativa e opressora (LOURO, 1997; MARIANO, 2005).

Percebe-se, então, que a construção do conceito de gênero está diretamente associada à luta e conquistas femininas (LOURO, 1997). Esse conceito começou a ser entendido pelos movimentos feministas como um instrumento explicativo para as desigualdades e discriminações históricas entre homens e mulheres (COSTA; LIMA, 2015).

Assim, devido às desigualdades, ao preconceito e à discriminação sofridos pelas mulheres, surgiram os Movimentos Feministas, que buscavam a garantia de direitos iguais entre homens e mulheres em todas as esferas da sociedade (AMORIM, 2011). De acordo com Narvaz e Koller (2006), o movimento surgiu no século XVII como forma de protestar contra a histórica opressão e dominação masculina sobre as mulheres.

\section{Os Feminismos: Suas Ondas e Abordagens}

Os movimentos feministas, como grupos organizados, surgiram na Europa Ocidental e tem o objetivo de confrontar a particular situação de subordinação das mulheres pelos homens (GUIMARÃES, 2005). Para Louro (1997), o principal objetivo das feministas, no início dos movimentos, foi de 
tornar visíveis aquelas (as mulheres) ocultadas historicamente pela segregação social e política, denunciando a ausência das mulheres na política, na ciência, nas letras e nas artes.

Bairros (1995, p.462) reflete o feminismo como "instrumento teórico que permite dar conta da construção de gênero como fonte de poder e de hierarquia que impacta mais negativamente sobre as mulheres. É a lente através da qual as diferentes experiências das mulheres podem ser analisadas criticamente”. Dessa forma, segundo Duarte (2003, p. 152), o Feminismo é considerado "em um sentido mais amplo, como todo gesto ou ação que resulte em protesto contra a opressão e a discriminação da mulher, ou que exija a ampliação dos próprios direitos civis e políticos, seja por iniciativa individual, seja de grupo" (DUARTE, 2003, p.152). O feminismo, então, é um movimento de contestação para a construção de uma justiça social para as mulheres. Isso quer dizer que o feminismo clama por mudanças nas ordens sociais, com o objetivo de rejeitar todas as formas de dominação (CRUZ, 2007).

É importante aqui esclarecer conforme citado por Auad (2003, p. 13) que há muitas pessoas que associam o feminismo à "imagem de mulheres que detestam homens, queimam sutiãs e que, como Napoleão, desejam dominar o mundo, detendo todo e qualquer poder". Esse fato contribuiu para uma visão pejorativa do feminismo difundida pelo senso comum, distorcendo e limitando sua natureza e seus objetivos (DUARTE, 2003; TEIXEIRA; CAPPELLE; OLIVEIRA, 2012).

Ou seja, é importante esclarecer que para esta pesquisa considera-se o feminismo como um movimento formado por mulheres críticas e questionadoras, que não desprezam o homem, mas sim o modelo de passividade e submissão imposto às mulheres historicamente, combatendo o machismo, o sexismo, a desvalorização das mulheres e do feminino. Assim, o feminismo é um movimento político formado principalmente por mulheres para combater a discriminação de gênero em todos os contextos sociais. 
Apesar de se usar o termo feminismo no singular, Auad (2003) defende que existem vários grupos de feminismos no mundo e no Brasil, defendendo ideais, valores e abordagens diferentes, sendo um movimento extremamente heterogêneo (COSTA; LIMA, 2015). Por esse motivo, Diniz (2012) afirma que o feminismo deveria ser tratado no plural, ou seja, feminismos.

Então, para este estudo, reconhece-se a pluralidade dos movimentos feministas, representando as mais diversas mulheres, com todos os perfis, características, perspectivas, especificidades e contextos. Esses diferentes movimentos foram e são formados pelos diversos momentos e contextos que perpassam o processo de construção dos movimentos feministas (CRUZ, 2007). Para Matos (2008, p. 351) essas diferentes abordagens dos movimentos feministas são importantes por deixar um "legado civilizatório inegável para as sociedades" nas quais têm se desenvolvido.

Calás e Smircich (1999, p. 274) estruturam as diferentes abordagens referentes às teorias feministas, destacando que essas abordagens são discursos que criticam o status quo, tendo o caráter político, reformista e transformador da sociedade. Cada abordagem defende suas perspectivas e contextos, entretanto, para as autoras, todas as perspectivas têm em comum "o reconhecimento da dominação masculina nos arranjos sociais e o desejo de mudanças nessa forma de dominação". Isso quer dizer que são abordagens que se cruzam e têm pontos semelhantes, atribuindo a cada perspectiva uma relevante contribuição para as questões de gênero em épocas e contextos diferentes.

A partir dessas diversas abordagens tratou-se da opressão sofrida pelas mulheres para a construção e a desconstrução do que é ser mulher na sociedade, dos fatores que perpetuam a desigualdade entre os gêneros e como reverter este quadro (NARVAZ; KOLLER, 2006). Dessa forma, apresenta-se as principais abordagens feministas de acordo com o enfoque dado por Tong (1994) e Calas e Smircich (1999) e, de acordo, com as três fases marcantes desse movimento, conhecidas como "ondas" do feminismo, 
levando-se em consideração os contextos político e social de cada onda (a quarta onda dos movimentos feministas será apresentada na próxima seção).

A primeira onda dos movimentos feministas, conhecida como sufragista, foi o movimento liberal. Esse movimento se originou com o capitalismo na Revolução Industrial nos séculos XVII e XVIII na França e Inglaterra (LIMA, 2009). As feministas liberais acreditavam que as mulheres sempre estiveram em desvantagem em relação aos homens, por motivos históricos e econômicos, e por isso, não tinham as mesmas oportunidades. Foi influenciado pelos ideais políticos de igualdade, liberdade e fraternidade, oriundos da revolução francesa, e marcado pela crescente demanda por mão-de-obra proveniente da revolução industrial, permitindo que as mulheres passassem a integrar o mercado de trabalho da época (CALÁS; SMIRCICH, 1999; NARVAZ; KOLLER, 2006).

Porém, nessa época, as mulheres não votavam e eram proibidas de ter propriedades em seu nome, deixando-as totalmente dependentes dos homens. Além disso, a participação feminina no trabalho era somente em cargos de subordinação, em postos de trabalho precários e com menor remuneração. Nessa linha teórica considerada reformista, as mulheres buscavam a equidade de gênero, principalmente relacionada aos direitos civis, políticos e econômicos, reivindicando a inserção das mulheres na sociedade e o acesso à educação (CALÁS; SMIRCICH, 1999; NARVAZ; KOLLER, 2006; LIMA, 2009).

Tong (1994) afirma que o movimento feminista liberal adotou a concepção de uma classe homogênea de mulheres, ou seja, que a situação de todas as mulheres era igual, e que a diferença de gênero entre homens e mulheres era proveniente somente das desigualdades econômicas entre eles, o que não era percebido na realidade. A atribuição de uma categoria homogênea de mulheres foi o principal limitador dessa teoria, passando a representar apenas os interesses das mulheres brancas, de classe média e de países desenvolvidos. Além disso, após o alcance das metas dessas 
feministas, que foi o direito ao voto pelas mulheres em vários países do ocidente, houve uma acomodação do movimento (LOURO, 1997).

A segunda onda dos movimentos feministas iniciou-se no século XX e foi caracterizada pela crescente inserção feminina no mercado de trabalho. Para Louro (1997), essa segunda onda foi marcada não apenas pelas preocupações sociais e políticas, mas também pelas construções teóricas acerca do conceito de gênero e dos estudos das mulheres. Teve seu início com o livro de Simone de Beauvoir, publicado em 1949, chamado O Segundo Sexo.

Essa obra mostrou que as reivindicações pelos direitos das mulheres estavam apenas começando e tinha a concepção da ruptura com o determinismo biológico, já que, para a escritora, "ninguém nasce mulher, torna-se mulher" (BEAUVOIR, 1980, p. 09). A autora traça um grande panorama histórico da dominação masculina, explicando como o papel das mulheres foi/é considerado secundário, além de defender as premissas de que as opções dos indivíduos não podem depender da sexualidade deles (CORREAA, 2004; CAPPELLE; MELO; SOUZA, 2013).

A obra de Beauvoir provocou grande impacto na sociedade pelo empreendimento em pesquisar sobre as mulheres e "influenciou sobremodo o pensamento feminista e tem contribuído para transformar não somente a visão de milhares de mulheres sobre a vida em sociedade, como também suas condutas" (SAFFIOTI, 1999, p.163). Dessa forma, o debate promovido pela autora foi muito importante por inspirar outras abordagens feministas, como a radical, a psicanalítica, a marxista e a socialista. Essas abordagens serão apresentadas a seguir.

A teoria feminista radical originou-se na década de 1960 e propõe a livre distinção de gênero ou de sexo para uma sociedade ideal, surgindo com a insatisfação do sexismo dos movimentos da época, pelos direitos civis e contra a Guerra do Vietnã. Nessa corrente, as feministas rejeitam todas as formas de dominação masculina e acreditam que o patriarcalismo é a origem da opressão feminina. Esse movimento é centrado nas mulheres e aspira 
uma nova ordem social, sem a subordinação das mulheres pelos homens (CALÁS; SMIRCICH, 1999).

A principal contribuição desse movimento foi a criação de ideais de mundos alternativos ao patriarcado, focando nos valores femininos de um modo geral. O movimento feminista radical conseguiu agregar representatividade: além das mulheres brancas e heterossexuais, mulheres de outras etnias e as lésbicas. Porém, como limitação, tem-se a utopia da total diferenciação de gênero com políticas separatistas, como a criação de organizações unicamente femininas e os espaços só de mulheres (TONG, 1994).

A escola feminista psicanalítica é uma abordagem que liga a mente dos sujeitos com as suas experiências de desenvolvimento. Tem origem na teoria freudiana e nas teorias sobre relação-objeto. Essa corrente considera que a ideia de que o masculino é melhor que o feminino está enraizada desde as experiências na infância e está impregnada no inconsciente da sociedade. Nessa abordagem, o homem e a mulher são diferentes porque possuem o desenvolvimento psicossexual (pessoal e social) distintos. Para uma sociedade livre da dominação masculina, essa vertente defende a ideia da mudança dos arranjos familiares, da maneira de como os pais são vistos pelos filhos (CALÁS; SMIRCICH, 1999; LIMA, 2009).

O feminismo marxista se baseia na crítica marxista de uma sociedade capitalista e do liberalismo político, sendo os gêneros como categorias sociais definidas pelas relações de dominação e opressão. Essa vertente se apropriou da ideologia da luta de classes proposta por Marx e Engels, considerando o gênero e classe como categorias sociais, caracterizadas pela opressão do sistema capitalista, isso quer dizer que as mulheres também são consideradas como uma classe oprimida por esse sistema. As feministas marxistas defendem que as desigualdades de gênero continuarão caso não haja mudanças estruturais na sociedade (CALÁS; SMIRCICH, 1999; LIMA, 2009). 
A partir das abordagens feministas marxista, radical e psicanalítica, surge a teoria feminista socialista com o objetivo de defender uma sociedade em que masculinidade e feminilidade são socialmente irrelevantes e que a segregação de gênero terminaria com a extinção do capitalismo e do patriarcado. Essa abordagem se originou devido ao fato de que o movimento feminista marxista considerava a opressão da classe operária mais importante que a opressão às mulheres. Além disso, criticou os movimentos radical e psicanalítico por serem generalistas e não levarem em consideração os contextos históricos e culturais (CALÁS; SMIRCICH, 1999).

Para as feministas socialistas, o gênero é formado socialmente por meio das junções entre sexo, raça, ideologia e opressão dos sistemas capitalista e patriarcal (CALÁS; SMIRCICH, 1999). Tong (1994) afirma que essa vertente tenta desenvolver teorias para explicar a relação entre capitalismo e patriarcalismo e que o grande ponto limitador dessa vertente é o seu caráter utópico, já que não há um sistema social com a capacidade de destruir os sistemas de opressão e acabar com a luta de classes.

Além das primeira e segunda ondas, tem-se a terceira onda dos movimentos feministas que surgiu na década de 1990 com o objetivo de descontruir e discutir as lacunas deixadas pela segunda onda. Tem a proposta da análise das diferenças, da diversidade e da produção discursiva da subjetividade. É nessa onda que se observa uma maior relação entre a academia e a luta das mulheres: nas universidades, em centros de estudos sobre a mulher, de gênero e femininos. O principal desafio nessa terceira geração do feminismo é pensar ao mesmo tempo na igualdade e na diferença para a construção das subjetividades masculina e feminina (NARVAZ; KOLLER, 2006) e romper com os pensamentos e regras universais (CRUZ, 2007).

Essa onda é conhecida como pós-feminismo e tem o objetivo de romper o significado de gênero como categoria fixa e imutável (MACEDO, 2006). Nessa vertente, troca-se as ideias unitárias de mulher e de identidade genérica feminina para tratar de conceitos acerca da identidade social e que 
o gênero seria mais uma questão relevante (RODRIGUES, 2005). Considerase, nessa onda, que o gênero é formado pela personalidade e comportamento e, também, pela forma como o corpo (sexo) aparece (MEYER, 2004). Essa perspectiva de gênero é problematizada por Butler (2003), desconstruindo a dualidade gênero e sexo, já que para a autora sexo é também discursivo, assim como o gênero, conforme já abordado no capítulo anterior. Essa onda também possui abordagens feministas que serão apresentadas a seguir.

A teoria pós-estruturalista/pós-moderna, advinda da terceira onda do feminismo, possui várias correntes distintas: feminismo francês, teoria anglo-americana e o feminismo pós-moderno. Essa abordagem questiona o conhecimento positivista (razão). Aborda que sexo e gênero são práticas discursivas que formam subjetividades específicas através do poder e da resistência na materialidade dos corpos. Esse movimento se dedicou ao estudo das diferenças, da diversidade e da produção discursiva da subjetividade com foco entre linguagem e conhecimento (CALÁS; SMIRCICH, 1999; TONG; 1994). Narvaz e Koller (2006) alegam que nessa época houve a passagem da luta política do movimento para a academia, na qual foram criados centros de pesquisa sobre gênero e feminismo nas universidades.

A teoria terceiro-mundista/pós-colonial critica a generalização das questões de gênero realizada pelas feministas do primeiro mundo das outras abordagens consideradas como teorias de gênero branca, de classe média e heterossexual, ou seja, seu caráter totalitário, não levando em consideração os outros contextos sociais e econômicos de todas as mulheres, bem como as relações de dominação do primeiro mundo com os outros países colonizados (CALÁS; SMIRCICH, 1999).

Todas essas teorias feministas permitem compreender as diferentes formas de construção social e individual das mulheres, refletindo sobre as relações de gênero. Dessa forma, cada linha de pensamento se direciona a perspectivas, aspectos e contextos específicos e o surgimento de novas abordagens é "para responder as limitações de outra e, embora pareçam 
independentes e diferenciadas, suas fronteiras não são muito nítidas" (CALÁS; SMIRCICH, 1999, p. 275).

Cabe destacar a crítica de Butler (2003) de que algumas abordagens teóricas feministas, com o objetivo de consolidar a representatividade das reivindicações e questionamentos, atribuíram um caráter universal à opressão sofrida pelas mulheres, ou seja, classificando as situações de todas as mulheres como homogêneas. Para a autora, o gênero não se dá de maneira coerente nas diversas situações e contextos históricos existentes na sociedade e deve-se repensar as restrições que as teorias feministas carregam na tentativa de representar as mulheres. Juntamente com Butler (2003), as feministas negras, latino-americanas, de países de Terceiro Mundo, de países ex-colônias e as lésbicas reprovaram essa tentativa de construção de um sujeito feminino universal por muitas feministas (MARIANO, 2005).

Dessa forma, a partir da publicação da obra de Hazel Cardy White Woman: Listen! Black Feminism and the Boundaries of Sisterhood, no início dos anos 80, expandiu-se o conceito de interseccionalidade e os estudos sobre raça, gênero e classe, constituindo um campo acadêmico especifico: o pensamento feminista negro (RODRIGUES, 2013). De acordo com Rodrigues (2013, p. 07) a interseccionalidade é uma:

Ferramenta teórico-metodológica fundamental para ativistas e teóricas feministas comprometidas com análises que desvelem os processos de interação entre relações de poder e categorias como classe, gênero e raça em contextos individuais, práticas coletivas e arranjos culturais/institucionais.

O movimento feminista interseccional surgiu com o objetivo de acabar com as formas de opressão interna dos movimentos, ou seja, acabar com a invisibilidade da categoria raça nos movimentos feministas, rompendo com as limitações do feminismo branco e sua característica de singularidade da luta feminista e da categoria gênero no movimento negro, criticando o 
sexismo existente (RODRIGUES, 2013). Para a autora, as mulheres negras foram posicionadas em uma situação muito desfavorável, sendo importante trazer a categoria analítica raça e suas especificidades para à luta das mulheres.

Nesse sentido, é importante considerar que as experiências de dominação dos homens têm certas peculiaridades dos contextos históricos, sociais e culturais em que as mulheres estão inseridas, para compreender a opressão por gênero (DINIZ, 2012). Portanto, são “[...] vários feminismos, que envolvem múltiplos interesses e que precisam tratar também da própria diversidade entre as mulheres, seja racial, étnica, seja de condição socioeconômica, de orientação sexual, de geração e de cultura”, ou seja, tal diversidade do feminismo deve levar em consideração as diversas realidades da condição das mulheres na esfera social (TEIXEIRA; CAPPELLE; OLIVEIRA, 2012, p. 77). Afinal, não há “A” mulher ou "O” homem, e sim diversos e diferentes mulheres e homens, conforme indaga Louro (1997).

É importante, também, apresentar como surgiu e se desenvolveu os movimentos feministas brasileiros.

\section{Os Movimentos Feministas no Brasil}

Os movimentos feministas no Brasil surgiram para desafiar a ordem conservadora que não considerava as mulheres como sujeitos de direitos, deixando-as fora da vida pública (PINTO, 2003). Dessa forma, esses movimentos contribuíram para a diminuição das desigualdades de gênero na sociedade brasileira, rompendo com a tradição cultural na qual as mulheres tinham somente papel nas atividades domésticas e na reprodução e os homens monopolizavam o espaço público (BELTRÃO; ALVES, 2009).

Deve-se considerar que os movimentos brasileiros não ocorreram de maneira isolada e homogênea, sofrendo influências do contexto mundial (COSTA, 2005; TEIXEIRA; CAPPELLE; OLIVEIRA, 2012). Porém, é importante destacar as especificidades da América Latina e do Brasil 
enquanto sociedades colonizadas, escravocratas e dominadas pela Europa para impulsionar o capitalismo mercantil (BITTENCOURT, 2015).

Nesse sentido, Pinto (2003) destaca que uma das características dos movimentos feministas brasileiros é sua fragmentação, com várias manifestações e muitos objetivos. Além disso, caracteriza o movimento feminista no Brasil, em seu início, como um movimento não popular, já que desde suas primeiras manifestações reuniu mulheres intelectuais (minorias) que se expressavam por meio de publicações, palestras, romances e peças de teatro.

Muzart (2003) afirma que as escritoras brasileiras com publicações de textos feministas em jornais e periódicos tiveram um importante papel de despertar a consciência feminina no Brasil, lutando pelos direitos à educação, à profissão, ao voto e até ao divórcio. Dessa mesma maneira, Pinto (2003) evidencia o feminismo na academia, com a participação significativa de professoras universitárias nos movimentos feministas na década de 1970, que passaram a produzir conhecimento acerca das temáticas relacionadas às mulheres, com projetos de pesquisa, dissertações e teses.

Para Pinto (2003), a popularização do movimento feminista brasileiro ocorreu ao longo de sua história pelo surgimento de novas formas de organização social pelo processo de urbanização, como aparecimento das classes operárias. Nesse sentido, Corrêa (2001) afirma que os movimentos feministas brasileiros tiveram seu auge na década de 1970 e articulou com outros grupos sociais, como os movimentos populares - pleiteando por melhores condições de vida -, os movimentos políticos - luta contra o racismo, direito à terra dos índios e contra a ditadura - e os movimentos dos homossexuais. Essa articulação se explica pelo contexto político em que o Brasil se encontrava: sob uma forte ditadura e marcado por profundas desigualdades sociais. Dessa forma, as propostas das brasileiras não eram específicas da condição das mulheres, unindo-se com outros movimentos (GUIMARÃES, 2005). 
Destacam-se, então, as três grandes ondas do feminismo brasileiro. A primeira onda, como em outros países, teve foco na luta por direitos políticos das mulheres, conhecido como movimento sufragista, requisitando o direito ao voto e o direito de serem votadas. Essa vertente é chamada por Pinto (2003, p. 14) como a onda "bem-comportada" do feminismo brasileiro, pelo fato de que as reivindicações eram apenas para a "incorporação da mulher como sujeito portador de direitos políticos", sem alterar a posição que os homens ocupavam na sociedade, sendo considerado um movimento conservador.

Ou seja, as feministas não confrontavam o poder, mas sim, buscavam apoio nele. Para atingir esse objetivo, as feministas criaram a Federação Brasileira para o Progresso Feminino (FBPF), sendo um grupo homogêneo formado por mulheres da alta elite brasileira (PINTO, 2003, p. 14). Essa primeira onda se manteve até 1932 , ano em que as mulheres brasileiras conquistaram o direito ao voto.

A segunda onda é conhecida como feminismo difuso, defendido principalmente por mulheres cultas, como professoras, escritoras e jornalistas. Essa onda surge como consequência da resistência das mulheres ao autoritarismo e à repressão dos regimes militares dominantes na época. As feministas se preocupavam com a educação das mulheres e abordavam sobre a dominação masculina e o interesse dos homens em manter as mulheres na vida privada, longe da vida pública, bem como com a redemocratização da política brasileira (PINTO, 2003).

A terceira onda do feminismo teve seu contexto marcado pela redemocrarização da política brasileira e manifestou-se no movimento anarquista e depois no Partido Comunista. Foi representado por mulheres militantes de esquerda, trabalhadoras e intelectuais, que defendiam a libertação das mulheres à opressão masculina de maneira radical. Essa onda articulava sobre a questão da exploração do trabalho, sobre a dominação dos homens sobre as mulheres e sobre a dupla jornada das mulheres, associada ao trabalho e aos papéis tradicionais de esposas e mães. 
E acreditava que a luta pelos direitos políticos beneficiaria poucas mulheres, trazendo as discussões para o mundo do trabalho, na qual o homem (patrão) era como o opressor identificado no capitalismo, lutando por grandes transformações (PINTO, 2003).

Pinto (2003, p. 91) reflete sobre o feminismo após a virada do século: “o feminismo acabou?". A pergunta é consistente pelo fato de que não há mais o mesmo feminismo da década de 1970 nem no Brasil e nem na Europa, marcado por grupos de reflexões e fortes manifestações. Porém, para a autora, com o início do milênio houve novas formas de pensamento e de posturas do movimento: houve a dissociação do pensamento feminista e o movimento, e também a profissionalização do movimento com o surgimento de ONGs especializadas para as questões das mulheres.

Nesse mesmo pensamento de que o movimento feminista não acabou, Matos e Paradis (2014) defendem a existência de uma nova onda do feminismo no Brasil e na América Latina. Para as autoras, a recente representatividade política, a implantação de políticas públicas e o constante fortalecimento das demandas cívicas das mulheres para com os Estados representa essa quarta onda do movimento.

Dessa forma, as feministas estão cada vez mais participando e ocupando os espaços sociais e fortalecendo a construção de ações concretas no Estado pela luta dos direitos das mulheres. Essa nova onda do feminismo de Matos e Paradis (2014) vai ao encontro do que Costa (2005) defende, segundo a autora o movimento feminista mudou, não é mais o movimento sufragista e emancipatório como em seu início e na década de 1970, mas sim vem enfrentando novas demandas e novos enfrentamentos na luta por políticas adequadas para as mulheres.

Pinto (2003) afirma que o movimento feminista no Brasil deve ser entendido como uma luta pela autonomia nos espaços políticos e pela condição de dominação vivida pelas mulheres, na qual existem diferentes mulheres confrontando distintos problemas. A autora concorda com Butler (2003) no sentido de que houve movimentações feministas com diferentes 
formatos, objetivos e ideologias, além de diversos graus de radicalidade no Brasil, ou seja, há uma multiplicidade de manifestações feministas para representar todas as mulheres, caracterizado como um movimento difuso.

Apesar de todos os movimentos feministas, de todas as iniciativas, lutas e conquistas, ainda permanece a realidade discriminatória na vida das mulheres. O fato é que há evidências de uma maior participação das mulheres na sociedade, porém há também a reafirmação de velhos estereótipos relacionados às atribuições das mulheres e dos homens no mundo do trabalho (RAMOS; PINTO, 2018).

\section{Considerações Finais}

Este artigo teve como objetivo apresentar as diferentes abordagens epistemológicas nos estudos sobre gênero e feminismos, com o intuito de mostrar as visões acerca das diferentes perspectivas utilizadas. Permitiu-se aprender de quais formas a categoria gênero vem sendo discutida no campo acadêmico, bem como apresentou-se as diversas abordagens dos movimentos feministas e suas principais ondas.

Destacamos aqui a complexidade desses conceitos e categorias, por possuírem um amplo espaço de disseminação nas diversas áreas do conhecimento e por serem discutidos em diferentes perspectivas teóricas, conforme apresentado nesta pesquisa. Esse fato ocorre porque a discussão sobre gênero e as diferentes abordagens feministas permeiam diversas questões nas relações sociais, como: desigualdades sociais, organização do trabalho, sistemas de poder, instituições normativas, simbólicas e culturais, entre outros fatores (COSTA; LIMA, 2015).

A expectativa deste artigo é que este esforço auxilie futuros pesquisadores no seu posicionamento frente à temática de gênero e feminismos. 


\section{Referências}

AMORIM, L. T. Gênero: uma construção do movimento feminista?. In: Anais II Simpósio Gênero e Políticas Públicas, 2011.

AUAD, D. Feminismo: que história é essa? Rio de Janeiro: DP\&A, 2003.

BAIRROS, L. Nossos feminismos revisitados. Estudos feministas, v. 3, n. 2, p. 458463, 1995.

BELTRÃO, K. I; ALVES, J. E. D. A reversão do hiato de gênero na educação brasileira no século XX. Cadernos de Pesquisa, São Paulo, v. 39, n. 136, p. 125-156, jan./abr. 2009.

BEAUVOIR, S. O Segundo Sexo. Rio de Janeiro: Nova Fronteira, 1980 [1949].

BITENCOURT, S. M. A contribuição de teóricas feministas para os estudos de gênero. Revista Ártemis, v. 16, n. 1, ago-dez, p. 178-185, 2013.

BITTENCOURT, N. A. Movimentos Feministas. InSURgência: revista de direitos e movimentos sociais, v. 1, n. 1, p. 198-210, 2015.

BRUSCHINI, C.; ARDAILLON, D.; UNBEHAUM, S. G. Tesauro para estudos de gênero e sobre mulheres. São Paulo: Fundação Carlos Chagas, 1998.

BUTLER, J. Problemas de gênero: feminismo e subversão da identidade. Trad. Renato Aguiar. Rio de Janeiro: Civilização Brasileira, 2003.

CALÁS, M. B.; SMIRCICH, L. Do ponto de vista da mulher: abordagens feministas nos estudos organizacionais. In: CLEGG, S.; HARDY, C; NORD, D. (Org.). Handbook de estudos organizacionais. v. 1. São Paulo: Atlas, 1999. 275-329 p.

CAPPELlE, M. C. A.; MELO, M. C. O. L.; SOUZA, N. L. Mulheres, Trabalho e Administração. Revista Interdisciplinar de gestão social, UFBA, v. 2, n. 2, p. 161191, 2013.

CORRÊA, M. Do feminismo aos estudos de gênero no Brasil: um exemplo pessoal. Cadernos Pagu, n. 16, p. 13-30, 2001.

CORRÊA, A. M. H. O assédio moral na trajetória profissional de mulheres gerentes: evidências nas histórias de vida. 2004. 184f. Dissertação (Mestrado em Administração) - Centro de Pós-Graduação e Pesquisa em Administração da Universidade Federal de Minas Gerais, Belo Horizonte, 2004.

COSTA, A. A. A. O movimento feminista no Brasil: dinâmicas de uma intervenção política. Revista Labrys, Estudos Feministas/Études Féministes, Brasília, v. 7, 2005. 
COSTA, T. C.; LIMA, R. L. Gênero e Tendências Contemporâneas: uma análise do Seminário Internacional "Desfazendo Gênero". Textos \& Contextos (Porto Alegre), v. 14, n. 2, p. 416-429, 2015.

CRUZ, L. A. Crítica epistemológica do feminismo. In: III Jornada Internacional de Políticas Públicas. Programa de pós-graduação em políticas públicas da Universidade Federal do Maranhão, p. 1-14, 2007.

DINIZ, A. P. R. Mulheres gerenciáveis? Uma análise dos discursos sobre as mulheres na revista Exame. 148p. 2012. Dissertação (Mestrado em Administração)Universidade Federal de Minas Gerais, Belo Horizonte.

DUARTE, C. L. Feminismo e literatura no Brasil. Estudos Avançados, São Paulo, v. 17 , n. 49 , p. 151-172, set./dez. 2003.

FRANZONI, G. S. C. C. O feminismo e a construção do conceito de gênero. In: XIV Simpósio Baiano de Pesquisadoras sobre Mulher e Relações de Gênero. Universidade Federal da Bahia, p. 21-34, 2008.

GROSSI, M. P. Identidade de gênero e sexualidade. Estudos de Gênero: Cadernos de área n. 9. Goiânia: Editora da UCG, 2000.

GUIMARÃES, M. F. Trajetória dos feminismos: introdução a abordagem de gênero. In: CASTILLO-MARTÍN, M.; OLIVEIRA, S. Marcadas a ferro. Brasília: Secretaria Especial de Políticas para as Mulheres, p. 77-92, 2005.

HARAWAY, D. Saberes localizados: a questão da ciência para o feminismo e o privilégio da perspectiva parcial. Cadernos Pagu, n. 5, p. 7-41, 1995.

LAMAS, M. Gênero: os conflitos e desafios do novo paradigma. Proposta, $\mathrm{n}^{\circ} 84 / 85$, p.12-25, 2000.

LIMA, G. S. Os desafios da carreira da mulher executiva no Brasil. 2009. 125f. (Mestrado em Administração) - Programa de Pós-Graduação em Administração da Pontifícia Universidade Católica de Minas Gerais, Belo Horizonte, 2009.

LOURO, G. L. Gênero, sexualidade e educação: uma perspectiva pósestruturalistas. Petrópolis: vozes, 6 a Ed., 179 p., 1997.

MACEDO, A. G. Pós-feminismo. Revista Estudos Feministas, v. 14, n. 3, p. 813-817, 2006.

MARIANO, S. A. O sujeito do feminismo e o pós-estruturalismo. Revista Estudos Feministas, v. 13, n. 3, p. 483-505, 2005.

MATOS, M. Teorias de gênero ou teorias e gênero? Se e como os estudos de gênero e feministas se transformaram em um campo novo para as ciências. Estudos Feministas, v.16. n.2, p. 333-357, 2008. 
MATOS, M.; PARADIS, C. G. Desafios à despatriarcalização do Estado brasileiro. Cadernos Pagu, n. 43, jul./ago., p. 57-118, 2014.

MEYER, D. E. Teorias e políticas de gênero: fragmentos históricos e desafios atuais. Revista Brasileira de Enfermagem, v. 57, n. 1, 2004.

MUZART, Z. L. Uma espiada na imprensa das mulheres no século XIX. Revista de Estudos Feministas, v. 11, n. 1, 2003.

NARVAZ, M. G.; KOLLER, S. H. Metodologias feministas e estudos de gênero: articulando pesquisa, clínica e política. Psicologia em Estudo, Maringá, v.11, n.3, pp. 647-654. set./dez., 2006.

NICHOLSON, L. Interpretando o gênero. Revista Estudos Feministas. Florianópolis, v. 8, n. 2, p. 09-41, 2000.

OLIVEIRA, A. V. A teoria de Judith Butler: implicações nas estratégias de luta do movimento feminista. In: XIV Simpósio Baiano de Pesquisadoras sobre Mulher e Relações de Gênero. Universidade Federal da Bahia, p. 01-20, 2008.

PINTO, C. R. J. Uma história do feminismo no Brasil. São Paulo: Fundação Perseu Abramo, 2003. 119 p.

PRAUN, A. G. Sexualidade, gênero e suas relações de poder. Revista Húmus, v. 1, n. 1 , p. 55-65, 2011.

RAMOS, H. S.; PINTO, R. A. B. Mulher como sujeito de pesquisa nos estudos organizacionais: um levantamento bibliométrico entre os anos de 2010 a 2017. In: V Congresso Brasileiro De Estudos Organizacionais, Curitiba-PR - Brasil, p. 1-19, 2018.

RODRIGUES, C. Butler e a desconstrução do gênero. Revista Estudos Feministas, v. 13, n. 1, p. 179-183, 2005.

RODRIGUES, C. Atualidade do conceito de interseccionalidade para a pesquisa e prática feminista no Brasil. In: X SEMINÁRIO INTERNACIONAL FAZENDO GÊENERO, Florianópolis, 2013.

SAFFIOTI, H. I. B. Primórdios do conceito de gênero. Cadernos Pagu, v. 12, p. 157$163,1999$.

SANTOS, J. A. Desigualdade Social e o Conceito de Gênero. Universidade Federal de Juiz de Fora, 2010. Disponível em: $<$ http//:www.ufjf.br/virtu/files/2010/05/artigo3a7.pdf>. Acesso em: 11 jul. 2017.

SCOTT, J. W. Gênero: uma categoria útil de análise histórica. Educação e Realidade, vol. 20, n. 2, p. 71-99, jul./dez. 1995.

SOUZA, E. M. Poder, diferença e subjetividade: a problematização do normal. Farol-Revista de Estudos Organizacionais e Sociedade, v. 1, n. 1, p. 103-143, 2014. 
SOUZA, E. M. Fazendo e Desfazendo gênero: a abordagem pós-estruturalista sobre gênero. In: CARRIERE, A. P; TEIXEIRA, J. C.; NASCIMENTO, M. C. R. Gênero e Trabalho: perspectivas, possibilidades e desafios no campo dos estudos organizacionais. Salvador: EDUFBA, 2016, 376 p.

TEIXEIRA, J. C.; CAPPELLE, M. C. A.; OLIVEIRA, M. L. S. Feministas? Não, femininas! Analisando visões sobre o feminismo no discurso de mulheres que vivenciaram o auge do movimento feminista brasileiro. Revista Sociais e Humanas, v. 25 , n. 1, p. 75-97, 2012.

TEIXEIRA, J. C. As artes e práticas cotidianas de viver, cuidar resistir e fazer das empregadas domésticas. 2015, 412 p. Teses (Doutorado em Administração) - Centro de Pós Graduação e Pesquisas em Administração da Universidade Federal de Minas Gerais, Belo Horizonte, 2015.

TONG, R. Feminist Thought: A comprehensive Introduction. London: Routledge, c. 1989, rep. 1994. 305p.

Recebido em janeiro de 2017. Aprovado em fevereiro de 2017. 